\section{Response to: 'The utility of the HEp-2000 antinuclear antibody substrate' by Lee et al}

The correspondence of Lee $e t a l^{1}$ questions why the recent paper $^{2}$ of the international consensus on ANA patterns (ICAP) consortium about the clinical relevance of HEp-2 indirect immunofluorescent assay (IIFA) patterns does not include the HEp-2000 substrate (Immunoconcepts, Sacramento, California, USA). The decision not to include the HEp-2000 substrate origins from the initial conception of ICAP: it was decided not to include manipulated cellular substrates. ${ }^{3}$ Since the HEp-2000 cells are transfected with the SS-A/Ro60 cDNA, this substrate was not incorporated in the consensus. Obviously, this decision is disputable and perhaps should be reconsidered in the near future. Indeed, it is to be taken into account that also the 'non-manipulated' substrates may be different. First, characteristics of the subcultures may have gradually deviated from the original HEp-2 cells. It is even argued that in time the HEp- 2 cells have been contaminated with HeLa-cells. ${ }^{4}$ Second, diagnostic companies use distinct fixation procedures that eventually also may affect the HEp-2 IIFA patterns. Cell cycle progression can also be manipulated in order to have more mitotic cells (HEp-20/10; Euroimmun, Lübeck, Germany). Differences in conventional HEp-2 substrates included in ICAP are most evident for the cytoplasmic Rods-and-Rings pattern (anticellular (AC)-23) because this pattern is restricted to HEp-2 cell slides from only certain manufacturers. ${ }^{3}$ Genetic manipulation, as in the case of the HEp-2000 substrate, obviously has an additional impact on the IIFA patterns observed.

As indicated by Lee et al, ${ }^{1}$ the HEp-2000 substrate has increased sensitivity for anti-SS-A/Ro60 antibodies. The IIFA pattern observed is referred to as 'atypical speckled'. This pattern, for reasons mentioned above not included in the ICAP classification tree, ${ }^{3}$ is characterised by nuclear/nucleolar staining in the interphase cells that have been transfected with the SS-A/Ro60 cDNA, that is, in about $30 \%$ of the cells. This pattern is very specific for the presence of anti-SS-A/ Ro60 antibodies either with or without anti-TRIM21/Ro52 and/or anti-SS-B/La antibodies. ${ }^{5}$ Transfection does not seem to affect most of the regular HEp-2 IIFA patterns, but the nuclear fine speckled pattern (AC-4) in conventional HEp-2 cells, as far as attributed to the presence of anti-SS-A/Ro60 antibodies, obviously will change. At the second ICAP workshop (September 2015, Dresden, Germany) it actually was discussed that anti-SS-A/Ro60 antibodies may reveal a defined subtype of the nuclear fine speckled pattern. ${ }^{67}$ Although no consensus was reached on this subtype yet, transfection with the SS-A/Ro60 gene in the HEp-2000 substrate will hamper the identification of such a pattern.

Evidently, the HEp-2000 substrate is more sensitive for the detection of anti-SS-A/Ro60 antibodies and this is relevant for those diseases that are associated with these antibodies. These diseases include the Sjögren's syndrome, cutaneous lupus erythematosus, congenital heart block and neonatal lupus. As recognised by Lee $e t$ al ${ }^{1}$ the HEp-2000 substrate may still miss detection of anti-SS-A/Ro60 antibodies. Therefore, it is internationally recommended for clinical suspicion of these diseases to always perform a screening for antibodies to extractable nuclear antigens, including SS-A/ Ro60. ${ }^{8}$ Adequate identification of these autoantibodies is particularly relevant for identifying fertile women at risk for the development of pregnancy complications such as the congenital heart block and neonatal lupus. Altogether only $1 \%-2 \%$ of the pregnant women with anti-SS-A/Ro60 antibodies experience these complications. ${ }^{9}$ Thus far, it has not been resolved which women are at risk. The study of Jaeggi et al indicated that high-level anti-SS-A/Ro60 and anti-TRIM21/Ro52 antibodies are associated with the occurrence of a congenital heart block, ${ }^{10}$ but to our knowledge this has not been confirmed by others. If, indeed, high levels of antibodies are required for this clinical manifestation it can be speculated that the anti-SS-A/Ro60 reactivity that is missed by the HEp-2000 substrate is clinically less relevant, but this may also hold for the anti-SS-A/Ro60 reactivity that is missed by the conventional HEp-2 substrate. Next, there is still debate which autoantibody is responsible for the congenital heart block. From animal studies, it is concluded that a subset of anti-TRIM21/Ro52 antibodies (anti-p200 peptide) can be responsible for this condition, ${ }^{11}$ but the correlation of anti-p200 to congenital heart block is not validated in the Research Registry for Neonatal Lupus cohort. ${ }^{12}$ In any case, anti-TRIM21/Ro52 autoantibodies do not give any nuclear HEp-2 IIFA pattern, even not on the HEp-2000 substrate. ${ }^{36}$ Finally, the pregnancy complications due to the anti-SS-A/ Ro60 and/or anti-TRIM21/Ro52 antibodies are most often the first clinical manifestations of autoimmunity in the mother, that is, before diseases like the Sjögren's syndrome or cutaneous lupus erythematosus become apparent. As long as the detection of these autoantibodies is not part of nationwide pregnancy screenings, the reduced sensitivity of the HEp-2 substrate for anti-SS-A/Ro60 antibodies is less relevant for identifying potential pregnancy complications.

Altogether, the question raised by Lee et $a l^{1}$ about not having integrated the HEp-2000 substrate in the ICAP classification is a valid question. Although ICAP initially decided not to include substrates that are (genetically) manipulated, this view might be reconsidered.

Jan Damoiseaux $\odot,{ }^{1}$ Edward K Chan ${ }^{2}$
${ }^{1}$ Maastricht University Medical Center, Maastricht, The Netherlands
${ }^{2}$ Department of Oral Biology, University of Florida, Gainesville, Florida, United States

Correspondence to Dr Jan Damoiseaux, Maastricht University Medical Center, Maastricht 6229 HX, The Netherlands; jan.damoiseaux@mumc.nl

Handling editor Josef S Smolen

Acknowledgements The authors acknowledge the contribution of the members of the ICAP executive board.

Competing interests None declared.

Patient consent for publication Not required.

Provenance and peer review Commissioned; internally peer reviewed.

(c) Author(s) (or their employer(s)) 2020. No commercial re-use. See rights and permissions. Published by BMJ.

Check for updates

To cite Damoiseaux J, Chan EK. Ann Rheum Dis 2020;79:e68.

Received 30 April 2019

Accepted 30 April 2019

Published Online First 14 May 2019

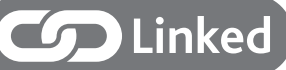

- http://dx.doi.org/10.1136/annrheumdis-2019-215519

Ann Rheum Dis 2020;79:e68. doi:10.1136/annrheumdis-2019-215610

ORCID iD 
Jan Damoiseaux http://orcid.org/0000-0003-4007-6985

\section{REFERENCES}

1 AYS LEE, Beroukas D, Roberts-Thomson PJ. The utility of the HEp-2000 antinuclear antibody substrate. Ann Rheum Dis 2020;79:e68.

2 Damoiseaux J, Andrade LEC, Carballo OG, et al. Clinical relevance of HEp-2 indirect immunofluorescent patterns: the International consensus on ANA patterns (ICAP) perspective. Ann Rheum Dis 2019;0:1-11.

3 Chan EKL, Damoiseaux J, Carballo OG, et al. Report of the first international consensus on standardized Nomenclature of antinuclear antibody HEp-2 cell patterns 2014-2015. Front Immunol 2015;6.

4 Ogura H, Yoshinouchi M, Kudo T, et al. Human papillomavirus type 18 DNA in so-called HEp-2, KB and fl cells - further evidence that these cells are HeLa cell derivatives. Cell Mol Biol 1993;39:463-7.

5 Damoiseaux J, Cohen Tervaert JW. From ANA to ena: how to proceed? Autoimmun Rev 2006;5:10-17.

6 Dellavance A, Alvarenga RR, Rodrigues SH, et al. Autoantibodies to 60kDa SS-A/Ro yield a specific nuclear myriad discrete fine Speckled immunofluorescence pattern. J Immunol Methods 2013;390:35-40.
7 Chan EKL, Damoiseaux J, de Melo Cruvinel W, et al. Report on the second international consensus on ANA pattern (ICAP) workshop in Dresden 2015. Lupus 2016;25:797-804.

8 Agmon-Levin N, Damoiseaux J, Kallenberg C, et al. International recommendations for the assessment of autoantibodies to cellular antigens referred to as anti-nuclear antibodies. Ann Rheum Dis 2014;73:17-23.

9 Brucato A, Cimaz R, Caporali R, et al. Pregnancy outcomes in patients with autoimmune diseases and anti-Ro/SSA antibodies. Clin Rev Allergy Immunol 2011;40:27-41.

10 Jaeggi E, Laskin C, Hamilton R, et al. The importance of the level of maternal anti-Ro/ SSA antibodies as a prognostic marker of the development of cardiac neonatal lupus erythematosus: a prospective study of 186 antibody-exposed fetuses and infants. J Am Coll Cardiol 2010;55:2778-84.

11 Salomonsson S, Sonesson S-E, Ottosson L, et al. Ro/SSA autoantibodies directly bind cardiomyocytes, disturb calcium homeostasis, and mediate congenital heart block. J Exp Med 2005;201:11-17.

12 Clancy RM, Buyon JP, Ikeda K, et al. Maternal antibody responses to the 52-kd SSA/ Ro p200 peptide and the development of fetal conduction defects. Arthritis Rheum 2005;52:3079-86. 